\title{
Hypoxia, angiogenesis, and metabolism in the hereditary kidney cancers
}

\author{
John C. Chappell, ${ }^{1}$ Laura Beth Payne, ${ }^{1}$ and W. Kimryn Rathmell ${ }^{2}$ \\ ${ }^{1}$ Center for Heart and Regenerative Medicine, Departments of Biomedical Sciences and Biomedical Engineering and Mechanics, Virginia Tech Carilion Research Institute, Roanoke, Virginia, USA \\ ${ }^{2}$ Vanderbilt-Ingram Cancer Center, Departments of Medicine and Biochemistry, Division of Hematology and Oncology, Vanderbilt University Medical Center, Nashville, Tennessee, USA.
}

\begin{abstract}
The field of hereditary kidney cancer has begun to mature following the identification of several germline syndromes that define genetic and molecular features of this cancer. Molecular defects within these hereditary syndromes demonstrate consistent deficits in angiogenesis and metabolic signaling, largely driven by altered hypoxia signaling. The classical mutation, loss of function of the von Hippel-Lindau (VHL) tumor suppressor, provides a human pathogenesis model for critical aspects of pseudohypoxia. These features are mimicked in a less common hereditary renal tumor syndrome, known as hereditary leiomyomatosis and renal cell carcinoma. Here, we review renal tumor angiogenesis and metabolism from a HIF-centric perspective, considering alterations in the hypoxic landscape, and molecular deviations resulting from high levels of HIF family members. Mutations underlying HIF deregulation drive multifactorial aberrations in angiogenic signals and metabolism. The mechanisms by which these defects drive tumor growth are still emerging. However, the distinctive patterns of angiogenesis and glycolysis-/glutamine-dependent bioenergetics provide insight into the cellular environment of these cancers. The result is a scenario permissive for aggressive tumorigenesis especially within the proximal renal tubule. These features of tumorigenesis have been highly actionable in kidney cancer treatments, and will likely continue as central tenets of kidney cancer therapeutics.
\end{abstract}

\section{Introduction}

Hereditary cancers in the kidney have provided a wealth of material to advance our understanding of cellular physiology. Most notably in the context of the mutation in the von Hippel-Lindau $(V H L)$ gene, carriers display an autosomal dominant risk for clear cell-type renal cell carcinoma (ccRCC) and other lesions throughout the body (1). This syndrome is an exceptionally valuable teaching tool in the medical school setting, illustrating concepts of hereditary cancer risk, loss of heterozygosity, sensor-driven signaling, genetic defects altering protein level regulation (ubiquitin/ proteasome degradation) as opposed to transcriptional regulation (transcription factors), tumor cellular metabolism, and growth factor-driven angiogenesis, among other topics. Studies in the biology of VHL disease and other kidney cancer syndromes led to key discoveries that cemented angiogenesis and metabolism as hallmarks of cancer. This Review will consolidate our knowledge around angiogenesis and metabolism, as learned from the vantage point of hereditary kidney cancer (Figure 1).

\section{VHL disease: an illustration of angiogenesis- fueled hereditary disease}

The VHL gene was discovered in 1993 in the pursuit of a familial autosomal dominant syndrome of numerous highly vascular tumors (2). Originally described as a syndrome, also known as familial cerebellar retinal angiomatosis, it was recognized in the

Conflict of interest: WKR receives institutional support for clinical trials from Pfizer, Novartis, Bristol-Myers Squibb, Calithera, Peloton, Tracon, and Roche.

Reference information: / Clin Invest. 2019;129(2):442-451.

https://doi.org/10.1172/JCl120855. early 1900s by German ophthalmologist Eugen von Hippel, who described angiomas in the eye in 1904, and Swedish pathologist Arvid Lindau described the angiomas of the cerebellum and spine in $1927(3,4)$. The term von Hippel-Lindau disease was first used in 1936; however, its use became common only in the 1970s. VHL disease's link to ccRCC was discovered much later, but as this tumor is also characterized by a vascular-rich malignancy, the association was natural.

VHL disease has a prevalence of 2-3 per 100,000 and an estimated incidence around 1 of 45,000 live births (5). Penetrance is $90 \%$ by age 65 , and the manifestations emerge over the lifetime of affected individuals.

The VHL gene is located on chromosome 3p25.1. The VHL protein (pVHL) is composed of at least two isoforms, both of which convey activity as the substrate-binding component of an E3 ubiquitin ligase complex. VHL is the centerpiece of a finely tuned rheostat system that regulates the response to low oxygen levels. Several targets of pVHL-mediated proteasomal degradation have been reported, but the canonical substrates include the hypoxia-inducible factors (HIF-1 $\alpha$ and HIF-2 $\alpha$ ). These transcription factors interact with pVHL via their oxygen-dependent degradation domains (ODDs) containing proline residue targets that undergo hydroxylation by a family of iron- and oxygen-dependent prolylhydroxylation (PHD) enzymes. Thus, in the presence of physiological oxygen levels, PHD enzymes place a prolylhydroxylation mark on the HIF ODD, rendering HIF proteins susceptible to $\mathrm{PVHL}$-mediated ubiquitylation and proteolytic degradation via the proteasome. Levels are kept low until there is a deficit in oxygen supply, at which point unhydroxylated HIF proteins are free to accumulate, heterodimerize with their obligate partner protein (HIF-1 $\beta$, also known as the aryl hydrocar- 


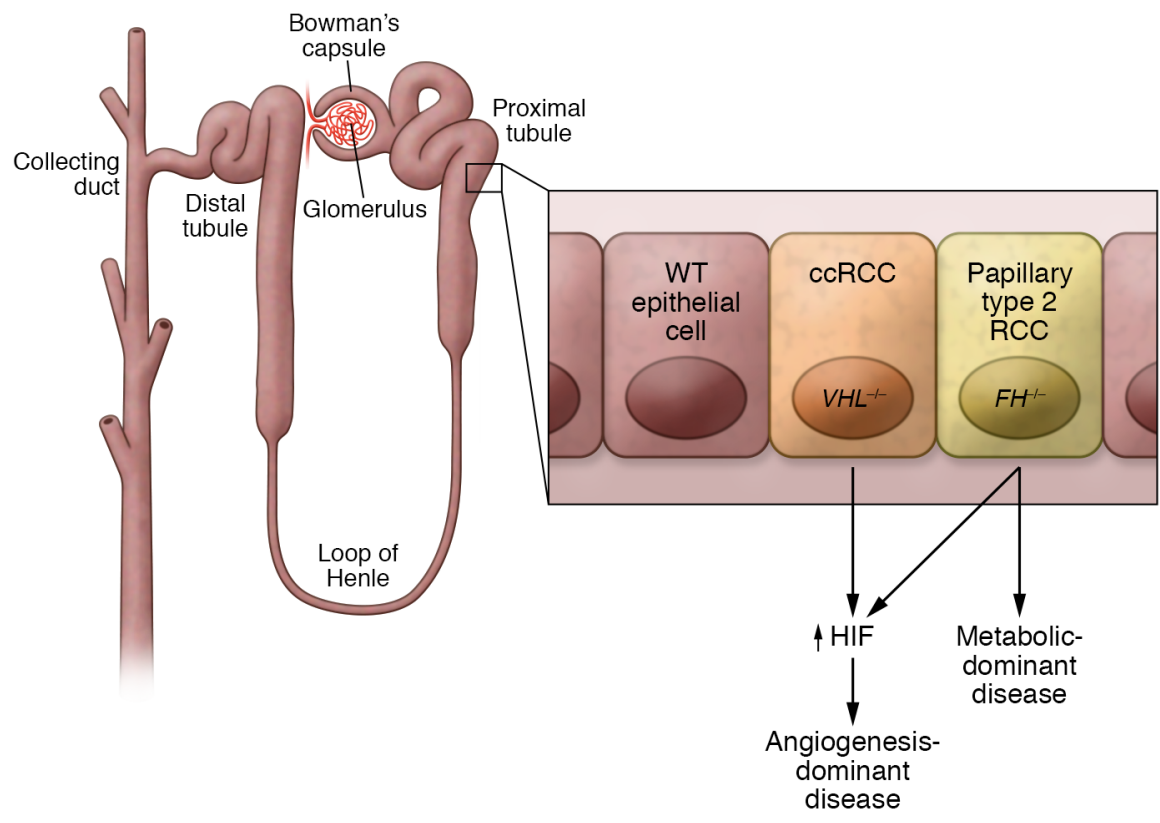

Figure 1. Common themes in hereditary kidney cancer syndromes. The two dominant forms of hereditary (and sporadic) RCC derive from cells in the proximal tubule. In spite of their common or similar origin, these tumor types have distinct genetics and biological characteristics. Although both VHL mutation, which is associated with clear cell type RCC, and FH mutation, which is associated with papillary-type 2 RCC, can deregulate HIF expression, these factors drive a differing balance of angiogenic and metabolic features, contributing to the overall pattern of the distinct diseases. bon receptor nuclear translocator [ARNT]), and execute their function as potent transcription factors (Figure 2).

In the absence of $\mathrm{pVHL}$, HIFs promote a unique angiogenic state of continuous mitogenic signaling. Thus, numerous investigations have detailed the effect of VEGF signals in this context. However, in the context of VHL disease, as well as in ccRCCs in general, a variety of $V H L$ mutations, of varying severity, are observed. Full genomic deletions are common, along with frameshift and truncating mutations, as are point mutations, which result in protein instability and mutations that retain partial functionality of the protein. Moreover, this disease gives rise to significant genotype-phenotype correlation, and the spectrum of proangiogenic effects varies according to the class of mutations that are observed.

VHL disease is subdivided into type 1 and type 2 . Type 1 conveys high risk for ccRCC, and is typically caused by complete loss of the protein. Type 2 is associated with missense mutations, along with risk for the syndrome of pheochromocytoma or paraganglioma. Type 2 is further subclassified based on risk of developing hemangioblastomas (type $2 \mathrm{~A}$ with lower risk, type $2 \mathrm{~B}$ with the highest risk) (6). Type 2C, typified by the L188V mutation, conveys risk for pheochromocytoma alone, and preserves HIF regulatory function (7). Finally, homozygosity for a rare mild mutation at the extreme C terminus, R200W, causes a familial autosomal recessive syndrome of erythrocytosis and polycythemia via a more subtle, and context-dependent, effect on HIF-2 $\alpha$ deregulation (8-10).

The common theme in differentiating these mutations is the extent to which pVHL interacts with and differentially regulates the canonical targets HIF- $1 \alpha$ and HIF- $2 \alpha$ (11). The differential impact of stable expression of one versus the other of these factors has direct implications for angiogenic signaling and will be discussed in detail later in this Review.

\section{HLRCC: an illustration of metabolically driven hereditary kidney cancer}

A second hereditary kidney cancer syndrome, called hereditary leiomyomatosis and RCC (HLRCC), provides additional insights into the core mechanisms of tumor cell fitness (12). HLRCC is another classical tumor suppressor autosomal dominant disease that conveys risk for leiomyoma (with leiomyomas in the uterus and skin predominating) and papillary-type 2 RCC. This syndrome is caused by germline mutations in a core Krebs cycle enzyme, fumarate hydratase (FH) (13). FH loss uncouples the Krebs cycle, driving up fumarate levels, and impairing cellular oxygenation as a result of the lack of reducing substrate (NADH) to drive electron transport (Figure 2).

How the FH mutation contributes to the development of a highly invasive and lethal kidney cancer remains an issue of active investigation. FH-mutant tumor cells are highly dependent on glycolysis and conduct reductive carboxylation, essentially reversing the Krebs cycle as a result of substrate availability. Constitutive HIF stabilization further contributes to metabolic aberrance in this cancer $(14,15)$. In FH-mutant tumor cells, accumulated fumarate mimics $\alpha$-ketoglutarate to directly inhibit PHD proteins. The result is lack of hydroxylation and pseudohypoxic stabilization of HIF factors in ccRCC (16).

A handful of other familial syndromes of kidney cancer risk (17) lend additional insight into the essential mechanisms of renal tumorigenesis. Birt-Hogg-Dubé syndrome conveys risk for a variety of RCC subtypes due to mutations in the folliculin (FLCN) gene. Tuberous sclerosis causes angiomyolipomas and risk for ccRCC due to mutations in TSC1 or TSC2 (tuberous sclerosis complex 1 and 2) that lead to activation of mTOR as well as HIF upregulation via enhanced cap-dependent translation; and hereditary papillary RCC, caused by activating mutations in cMET. Each of these mutations directly or indirectly impacts HIF signaling, tumor angiogenesis, and metabolism.

\section{HIF/hypoxia, a central mediator of renal tumor risk HIF $\alpha /$ HIF $\beta$ complex, hypoxia, and transcription activity. The capacity to detect and adapt to changes in oxygen is critical for cellular and whole-organism homeostasis, representing a critical}




\section{A Normoxic cellular metabolism}

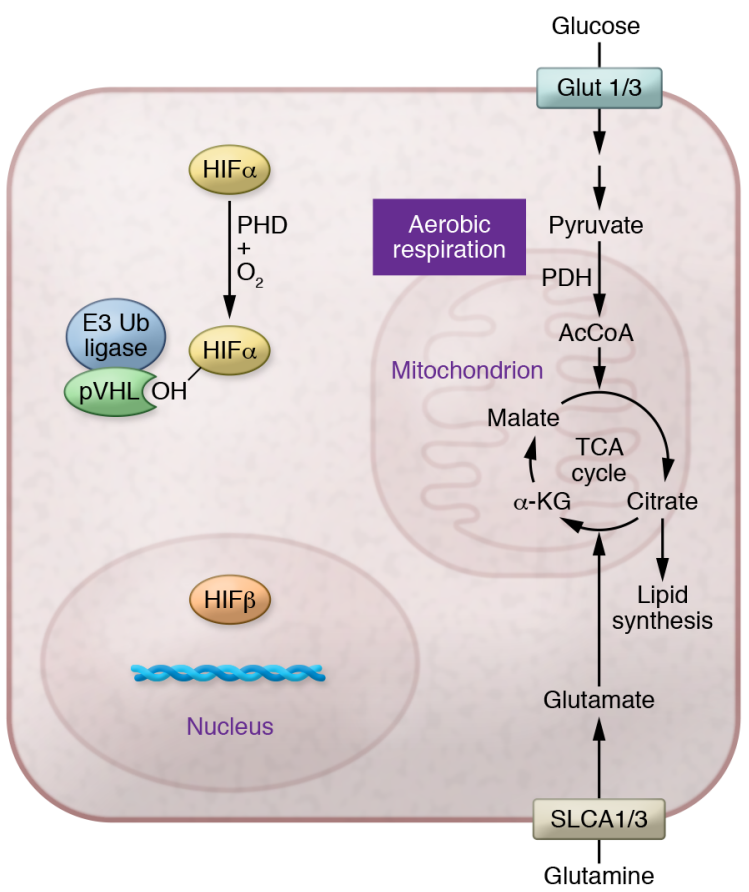

\section{B VHL-deficient RCC metabolic reprogramming by HIF}

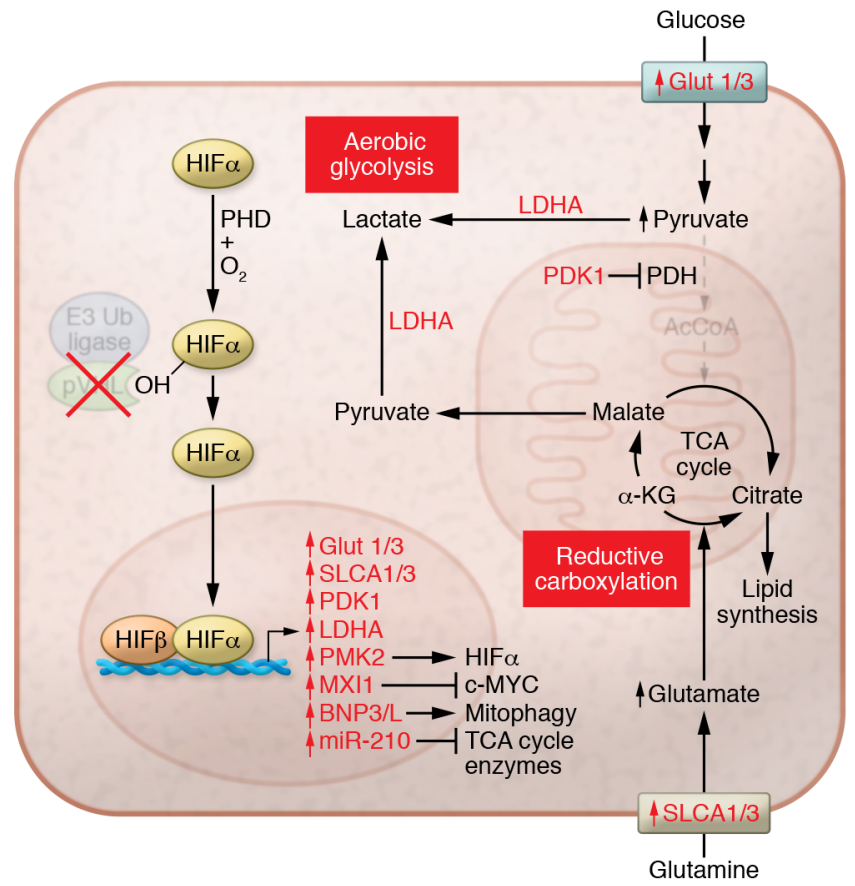

Figure 2. HIF-mediated metabolic reprogramming in VHL-deficient RCC. Germline mutations that render the tumor suppressor gene VHL defective, as observed in a majority of clear cell renal carcinoma cells (ccRCC), interfere with pVHL-mediated proteolysis of HIF $\alpha$ (compare a classic model of cellular metabolism in A, with pseudohypoxic HIF-driven RCC metabolic reprogramming in B). Stabilized HIF $\alpha$ translocates to the nucleus, where it dimerizes with $\mathrm{HIF} \beta$ and directly upregulates transcription of genes related to cellular metabolism, among hundreds of others. HIF reprograms metabolism away from aerobic respiration and toward aerobic glycolysis by increasing conversion from pyruvate to lactate (via upregulation of LDHA) and by blocking pyruvate conversion to acetyl-CoA by PDH (via upregulation of PDK1). HIF increases metabolic nutrients by upregulating transporters for both glucose (CLUT1 and GLUT3) and glutamine (SLCA1 and SLCA3), thereby increasing rates of glycolytic and reductive carboxylation pathways, respectively. In addition, HIF mediates a reduction in aerobic respiration by upregulating BNIP3 and BNIP3L, which leads to selective mitochondrial degradation. HIF interferes with TCA cycle enzymes via miR-210, which disrupts formation of Fe-S clusters necessary for catalysis. Upregulation of the transcription suppressor MXI1 represses c-MYC expression that greatly facilitates the metabolic shift in cancer cells. HIF amplifies its own transcriptional activity by upregulating the HIF $\alpha$ cofactor PKM2. Ub, ubiquitin. $\alpha-$ KG, $\alpha$-ketoglutarate.

evolutionary adaptation of multicellular organisms and enabling survival over time. Nearly every mammalian cell (18) responds to reduced oxygen availability through activation of the transcription factor HIF (19-22).

When conditions allow the two isoforms of HIF $\alpha, \mathrm{HIF}-1 \alpha$ and HIF- $2 \alpha$, to be stabilized, they are subsequently translocated into the nucleus via binding with HIF-1 $\beta$ (23). There, the HIF $\alpha / \beta$ dimer binds to hypoxia response elements (HREs) located often in the proximal promoters of target genes, promoting their transcription. Interplay with other DNA-binding proteins enables cooperative binding or coactivation of HIF, fine-tuning the activation of HIF targets $(20,24)$. While there is some redundancy between HIF-1 and HIF-2 targets, inactivation of each leads to unique phenotypes, perhaps due to their tissue-specific and temporally specific expression patterns (25-27).

In the presence of hypoxia, HIF activation reprograms cellular oxidative metabolic mechanisms, representing an elegant bioenergetic adaptation enabling cells to mitigate toxic reactive oxygen species (ROS) and to preserve macromolecular synthesis in response to oxygen availability. The reprogramming of numerous and varied cellular systems by HIF in tumorigenesis, including stem cell maintenance, growth factor signaling, epithe- lial-mesenchymal transition, invasion, metastasis, angiogenesis, and metabolism (28-31), underscores the consequential role of HIF in cancer progression.

HIF-1 versus HIF-2. Both HIF- $1 \alpha$ and HIF-2 $\alpha$ appear to be involved in ccRCC initiation $(32,33)$. However, it is thought that HIF- $1 \alpha$ functions as a tumor suppressor in ccRCC by attenuating VHL-deficient tumor cell proliferation (34) and is not active in some ccRCCs $(35,36)$. Deletions of chromosome $14 \mathrm{q}$, which harbors the HIF-1A locus, occur in ccRCC and indicate poorer outcomes (37-39). Conversely, HIF-2 $\alpha$ consistently functions as an oncoprotein in ccRCC $(34,36,40)$. In the VHL-deficient setting, HIF-2 $\alpha$ upregulates targets involved in angiogenesis (41-44), oxidative stress resistance (45), mitochondrial biogenesis (34, 46-48), metastasis $(49,50)$, and autonomous proliferation and cell cycle $(36,43,51,52)$. In addition, HIF- $2 \alpha$, but not HIF- $1 \alpha$, can override pVHL's suppressive function $(34,40,53)$. Consequently, ccRCCs that express only HIF- $2 \alpha$ are characterized by increased cell proliferation and adverse prognosis $(36,45,54,55)$. Elimination of HIF- $2 \alpha$ in vivo attenuates tumorigenesis in VHL-deficient RCC cells $(56,57)$. These and other differential impacts of HIF-1 $\alpha$ versus HIF-2 $\alpha$ (58) present exploitable and attractive mechanisms for targeted therapies in ccRCC. 
A WT

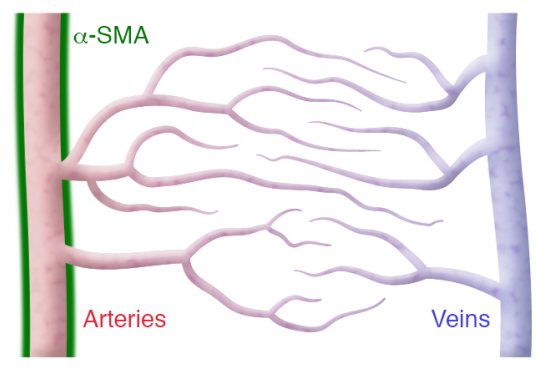

B VHL mutant

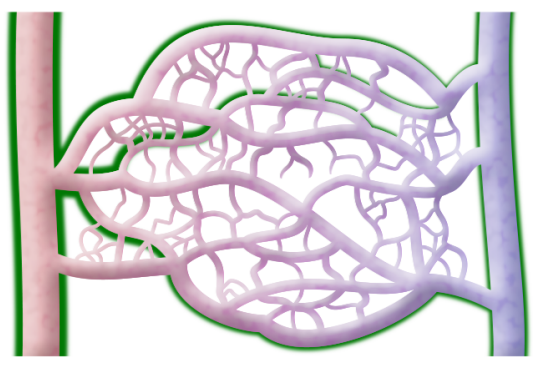

Figure 3. Vascular dysmorphogenesis during VHL mutations. Inducing VHL mutations experimentally (compare WT conditions in A with VHL mutant condition in B) leads to vascular abnormalities characterized by an ectopic expression of smooth muscle $\alpha$-actin ( $\alpha$-SMA; green) by vascular pericytes and vascular patterning defects, including elevated vessel density and the development of arteriovenous shunts spanning major arteries/ arterioles (light red) and venules/veins (light blue).

\section{Angiogenesis, a theme in hereditary kidney cancer risk}

Misregulated vascular growth and remodeling contribute to the onset and progression of numerous tumor types (59), and these processes are particularly relevant to hereditary kidney cancers. Blood vessel development matches metabolic activity and tissue oxygenation under normal conditions (60). However, disrupted metabolism and oxygen sensing mechanisms in inherited kidney cancers induce structural changes of the blood vasculature, seen prominently in vascular remodeling downstream of HIF misregulation $(61,62)$, often via VHL mutations (63-65). Tumor angiogenesis, or growth of new vessels from existing blood vasculature, is driven primarily by aberrant increases in VEGF-A, which is often induced by tumor hypoxia as the lesion expands, but also results from primary HIF pathway defects (64). Perturbations within other phases of vascular growth $(66,67)$ also contribute to and accelerate tumor vascularization. For instance, PDGF-BB signaling, an essential pathway for vessel maturation through mural cell recruitment (68-71), can be disrupted directly and indirectly by HIF-VEGF misregulation (72), especially in the tumor context (73-77). Notch signaling has also been implicated in promoting tumor vascularization (78-82), as Notch receptors and ligands regulate not only endothelial phenotypic heterogeneity during sprouting angiogenesis $(72,83,84)$, but also arterial-venous specification (85-87) and vessel maturation via mural cell investment (88-90). In addition to crosstalk within these signaling networks, molecular cues from the angiopoietin (ANGPT)/Tie pathway also coordinate the balance between (a) vascular plasticity and endothelial cell sprouting, primarily via ANGPT2-induced destabilization (91), and (b) vessel maturation via long-term investment of pericytes and vascular smooth muscle cells, which occurs downstream of ANGPT1-Tie2 interactions (92). In the context of renal cancer vascularization, these molecular pathways, among others, contribute to a complex pattern of angiogenesis and neovessel formation, as well as to the misregulation of vessel stabilization and maturation (93). They may, therefore, offer unique targets for modulating not only initial tumor vascularization, but also additional vessel remodeling processes that likely exacerbate tumor progression and undermine effective chemotherapeutic delivery.

\section{Angiogenesis in VHL disease - beyond the kidney}

Aberrant vascular remodeling often occurs in hereditary kidney cancer diseases - VHL disease being a notable example. High metabolic demand and oxygen consumption within the kidney compound disease-related defects in the mechanisms regulating these activities, thereby fueling the excessive proangiogenic signaling described in the previous section. These defects can lead to disease manifestations in tissues beyond the kidney, where abnormal vascular growth and remodeling contribute to additional pathologies. For instance, brain, spinal cord, and eye/retina hemangioblastoma formation is commonplace in VHL disease $(94,95)$, owing in part to disruption of the VEGF-A $(96,97)$ and Notch pathways (98), among others. Dysfunction in HIF signaling is also likely involved in the aberrant vessel remodeling found in nonkidney tissues, as recent studies have implicated this pathway, and downstream mediators such as ANGPT-like 4 (ANGPTL4), in angiogenesis-related conditions including pterygia (99), uveal melanoma (100), and proliferative retinopathies (101-103).

Increased insight into how angiogenesis defects lead to clinical manifestations of ocular VHL disease, such as retinal capillary hemangioblastoma $(\mathrm{RCH})$ formation, will advance future therapies as well as enhance the diagnostic strategies of ophthalmological examination of VHL patients (104-106). To better understand retinal vascular malformations in the VHL mutation scenario, we recently examined the retinal vasculature using inducible mouse models of type 1 (null) and type 2B (murine G518A representing human R167Q) $V h l$ mutations $(6,11,107)$. Retinal vessels of type 2B Vhl-mutant animals displayed hallmarks of an accelerated progression toward an arterial phenotype, including ectopic expression of vascular smooth muscle contractility proteins in microvascular pericytes (Figure 3 and ref. 98). We further found that both types 1 and $2 \mathrm{~B}$ genetic mutations resulted in abnormal angiogenic remodeling and changes in stage-specific vascular density (Figure 3 and ref. 98). These observations were consistent with a zebrafish model of VHL-associated retinopathy in which retinal angiogenesis and vessel leakage contributed to macular edema and retinal detachment (108). Blocking VEGF signaling in this type $1 \mathrm{Vhl}^{-/-}$model improved retinopathy outcomes (108), though recent studies have cautioned against sustained anti-VEGF interventions in the eye, as they may have deleterious effects on retinal neurons (109-111). Current treatment of ocular VHL disease includes systemic or intravitreal administration of anti-VEGF agents, laser photocoagulation, and cryotherapy (112), though clinical management remains a challenge because of the likelihood of new $\mathrm{RCH}$ formation and the frequent presence of multiple lesions in both eyes.

Aberrant blood vessel formation also gives rise to hemangioblastomas in the cerebellum and spinal cord of VHL patients (94, $113,114)$. Similarly to the kidney, these tissues have high metabolic 
demands and minimal to no energy reserves, which exacerbate genetic defects in mechanisms regulating metabolism and oxygen sensing (114). While VHL-mediated kidney cancer involves vascular remodeling via angiogenesis, hemangioblastoma formation in neurological tissues of VHL patients may also involve vasculogenic processes $(113,115,116)$. The precise cellular contribution of vascular cells versus tumor "stromal" cells to the dense vascularity of hemangioblastomas remains an open question (113); it is clear, however, that excessive proangiogenic factors such as VEGF-A, PDGF-BB, and EGF drive lesion growth $(117,118)$. For these reasons, antiangiogenesis strategies initially developed to treat kidney cancers, and specifically VHL-associated ccRCC, are being adapted to manage CNS hemangioblastomas untreatable by surgical resection or radiation therapy $(117,119,120)$.

\section{Antiangiogenic targeting in RCC}

Altered hypoxia signaling and metabolism in renal cell carcinoma, as seen in VHL disease (121), drives angiogenic pathway activation, leading to the rationale for targeting signals involved in vascular remodeling $(122,123)$. Development of anti-VEGF therapies in particular has focused on dampening VEGF signaling by reducing ligand levels (e.g., the VEGF-A-targeting antibody bevacizumab) or interfering with tyrosine kinase activity and receptor phosphorylation (e.g., axitinib, pazopanib, sorafenib, sunitinib). These agents transformed the care of patients with RCC (122). Increasing appreciation for proangiogenesis resistance mechanisms (124) has inspired development of agents targeting additional growth factor pathways such as FGF (lenvatinib, targeting FGFR) and HGF (cabozantinib, targeting the HGF receptor cMET). Clinical trials involving anti-VEGF therapy for RCC patients $(125,126)$ highlight the need for increased insight into more effective uses of antiangiogenic agents, potential combinatorial approaches such as with immunotherapy treatment $(127,128)$, and additional molecular targets intersecting with VEGF signaling.

Because HIF signals provide critical regulation of VEGF-A activity, this pathway has gained significant attention in the development of antiangiogenesis therapies. For example, acriflavin, which blocks HIF-1 dimerization, has shown promise in reducing tumor growth and associated angiogenesis in preclinical models $(129,130)$. Multimodal therapy involving HIF-1 $\alpha$ inhibition alongside VEGF-A inhibition and hypoxia-activated chemotherapy inhibits angiogenesis and cancer stem cell-like proliferation/survival in sarcomas (131), warranting validation of this approach for treating RCC. HIF-2 antagonists (such as PT2399 and PT2385) are also in development and show early indications of efficacy in treating a subset of ccRCCs $(41,132,133)$, though divergent responses to HIF-2 inhibition underscore the importance of careful inclusion of key biomarkers in clinical trial design (134).

\section{Hypoxia and metabolism in promoting kidney cancer risk}

Glycolysis and glutaminolysis. Uncontrolled proliferation of cancer cells requires increased synthesis of cellular components such as amino acids, lipids, and nucleotides, to meet basic tumor demands. Under normal oxygen conditions, energy is generated by the complete oxidation of glucose via aerobic respiration. However, independent of oxygen availability, cancer cells transition to aerobic glycolysis that promotes anabolic metabolic flux (135). This metabolic reprogramming, referred to as the Warburg effect in cancer cells (136), is mediated by HIF-1 $(52,137-140)$. To offset the energetic inefficiency of glycolytic metabolism, HIF-1 activates expression of the glucose transporters GLUT1 and GLUT3 to increase glucose uptake for glycolysis $(141,142)$. In addition, HIF-1 reprograms metabolism by inducing expression of glycolytic enzymes (142-148). In particular, HIF-1 inhibits conversion of pyruvate to acetyl-CoA (AcCoA) by pyruvate dehydrogenase (PDH) and subsequent entry into the TCA cycle, by regulating (a) PDK1, encoding pyruvate dehydrogenase kinase $1(149,150)$, which inactivates PDH; and (b) LDHA, encoding lactate dehydrogenase A $(142,151)$, which converts pyruvate to lactate in glycolytic metabolism. In so doing, HIF-1 shuttles glucose away from respiration and into glycolysis. HIF-1 also activates mitochondrialselective autophagy via regulation expression of BCL-2 family member BNIP3 and its ligand, BNIP3L, thereby preventing glucose and fatty acid oxidative metabolism $(152,153)$. Additionally, HIF-1 interferes with components of the TCA cycle and electron transport chain via activation of microRNA-210 (miR-210) (154156). However, despite these diverse strategies of HIF-1 to reprogram metabolism, oxidative respiration is not completely abolished. Consequently, by activating the Lon protease $(L O N)$ gene, HIF-1 improves efficiency of electron transport (157). However, overall reduction in electron transport efficiency in hypoxic conditions leads to increased ROS (158). The switch from oxidative to glycolytic metabolism pertains to ATP maintenance as well as toxic oxidant accumulation (139).

HIF's metabolic reprogramming of cancer cells is amplified by the glycolytic enzyme pyruvate kinase M2 (PKM2) in a positivefeedback mechanism. As an alternative splice product encoded by the PKM2 gene (159), PKM2 is expressed in the embryo and in cancer cells. In catalyzing the conversion of phosphoenolpyruvate to pyruvate, PKM2 is an important determinant in the glycolytic pathway. PKM2 contributes to enhanced lactate production seen in some cancer cells following hydroxylation by PHD3, potentiating PKM2 function as a HIF-1 coactivator (160). In turn, this coactivation leads to transactivation of HIF-1 target genes, which includes those encoding both PHD3 and PKM2. The HRE located in the proximal PKM2 promoter is recognized and activated by HIF- $1 \alpha$ and HIF-1 $\beta$, but not HIF-2 $\alpha$ (160). Therefore, by elevating PKM2 and PHD3 expression, HIF-1 may boost its own activity and enhance the Warburg effect observed in cancer cells (160).

In addition to glucose, glutamine is a key energy-producing nutrient that supports proliferating cells (Figure 2). Reductive glutamine metabolism provides vital metabolic intermediates for macromolecule synthesis. In hypoxic or highly proliferating cells, such as cancer cells, glutamine is not fully oxidized, but is rather used to generate citrate through reductive carboxylation (RC) of $\alpha$-ketoglutarate to provide intermediates (e.g., AcCoA) for lipid synthesis, which is otherwise primarily fueled by glucosederived pyruvate (161-165). VHL-deficient RCC cells, which show constitutive activation of HIF- $1 \alpha$ and/or HIF-2 $\alpha$ (166), synthesize lipids via RC-derived AcCoA rather than through glycolysis. Glucose-derived lipid synthesis is restored in this setting following introduction of wild-type VHL (163), demonstrating a HIF-mediated metabolic shift to RC in the VHL-deficient cells. 
A prominent mechanism by which HIFs execute this metabolic shift and thereby abrogate cellular respiration is through the oncogenic transcription factor c-MYC, known to induce proliferation. In contrast to HIF- $2 \alpha$ (61), HIF- $1 \alpha$ inhibits c-MYC activity both through transcriptional repression, by activating the GTP-binding protein MXI1, and through targeted proteolysis in VHL-deficient RCC. Consequently, the metabolic transcriptional profile in VHLdeficient ccRCC is altered with HIF-1-mediated loss of c-MYC, enhanced by the concomitant loss of the c-MYC-dependent transcriptional coactivator PGC-1 $\beta$ (52).

In conjunction with reductive metabolism of glutamine, HIF also influences glutamine signaling (167). The function of glutamate receptors is well documented in various cancer types (168), and HIF enhances glutamine signaling to drive tumor progression. Specifically, HIF triggers expression of AMPA-type glutamate receptors and membrane glutamate transporters that activate SRC family kinases and related signaling pathways. As a result, proliferation, survival, migration, and invasion are enhanced in ccRCCs and VHL-null cells (167).

Alternative regulatory metabolic features. As an example of the broad-reaching impact of metabolic derangement related to HIF biology, O-GlcNAcylation, the posttranslational process by which $\mathrm{O}$-linked $\beta$ - $N$-acetylglucosamine (O-GlcNAc) is added to intracellular proteins, impacts the hydroxylation of HIF-1 in cancer cells. $\mathrm{O}-\mathrm{GlcNAc}$ modifies intracellular proteins directly or indirectly as a response to changes in nutrient levels or stress (169). Elevated levels of O-GlcNAcylation have been reported in cancers (170) and are indicated in the reprogramming of cancer cell metabolism (171). HIF-1 $\alpha$ hydroxylation by PHD, interaction with pVHL, and proteasomal degradation are regulated by O-GlcNAcylation, though not via direct O-GlcNAc modification. Further, O-GlcNAcylation-mediated changes in metabolic flux required HIF- $1 \alpha$ hydroxylation in vitro (171).

HIF activities extend beyond angiogenesis in influencing the microenvironment. HIF expression in immune cells induces various aspects of host innate and adaptive immune function in response to hypoxia, triggering tissue damage and immune cell dysfunction (172). In the microenvironment of ccRCC, as a brief example, $\mathrm{CD} 8^{+} \mathrm{T}$ cells harbor distinct metabolic defects that restrict their ability to activate in response to conventional stimuli (173). Much more work is needed to fully understand the impact of the unique metabolic features of kidney tumors to alter the spectrum of tumor promotion.

\section{Imaging angiogenic and metabolomic defects in RCC risk}

Recent advances in medical imaging technology have expanded the clinical armamentarium for assessing and managing kidney cancer risk, specifically through monitoring of tumor-associated vascular remodeling and metabolic defects. Dynamic contrastenhanced MRI (DCE-MRI) is one such modality that facilitates noninvasive evaluation of RCC blood perfusion and microvessel leakage, correlative indicators of increased angiogenesis (174-176). Perfusion CT offers additional insight into tumor vascularity and blood flow $(177,178)$, with dynamic enhanced CT of RCC tumors capturing spatial heterogeneities and "hot spots" of increased microvascular density (179). PET, in conjunction with markers such as ${ }^{15} \mathrm{O}$-labeled water $\left(\mathrm{H}_{2}{ }^{15} \mathrm{O}\right)$, can also be applied to measure tumor blood flow $(180,181)$, but challenges remain in applying this modality for longitudinal assessment of RCC (180). Advances in ultrasound imaging have further extended the clinical utility of this imaging technique, as Doppler perfusion imaging and 3D scanning methods provide real-time measures of tumor morphology and vascularity $(180,181)$. Tumor vascularization imaging by ultrasound, along with MRI and PET, has recently benefited from the development of molecular imaging strategies whereby proteins involved in angiogenesis are labeled by contrast agents (182-184). Sprouting endothelial cells express high levels of VEGFR-2 to mediate VEGF signaling and the integrin $\alpha_{v} \beta_{3}$, which facilitates migration along surrounding extracellular matrix. These proangiogenic mediators, among others, have received significant attention in the development of molecular imaging techniques (185-188). Continued innovation in developing cancer imaging modalities and contrast enhancement will expand our understanding of the biology underlying RCC angiogenesis and enhance clinical care in monitoring treatment efficacy and disease progression using vascular biomarkers.

Metabolomic defects in RCC offer another disease feature that can be assessed noninvasively via the aforementioned imaging modalities (189). In particular, elevated glucose uptake owing to increased metabolic activity in RCC can be monitored using ${ }^{18} \mathrm{~F}$-labeled fluorodeoxyglucose (FDG) in conjunction with PET/ CT, particularly in detecting metastatic lesions (190-193). Variability in tumor FDG uptake, however, remains a key limitation in assessing primary RCCs (194) and can also hamper comprehensive evaluation of secondary RCC metastases, which may exhibit differential expression of glucose transporters and therefore wide-ranging FDG uptake capacities (195). For these reasons, complementary approaches are being developed to harness RCC metabolic defects for diagnostic imaging. Carbon-11 $\left({ }^{11} \mathrm{C}\right)$-acetate, for instance, can be rapidly taken up by tumor cells and converted to AcCoA, which contributes to synthesis of cell membrane fatty acids, a process that is accelerated during tumor cell proliferation (196). Coupled with PET imaging, this tracer has shown promise in predicting RCC response to the tyrosine kinase inhibitor sunitinib $(196,197)$. Membrane lipid synthesis also involves the generation of phosphatidylcholine following choline consumption by tumor cells (198), thus providing a rationale for developing ${ }^{11} \mathrm{C}$-choline PET/CT as a complementary approach to evaluating primary RCC and associated metastatic disease (199). Accelerated tumor cell proliferation can also be exploited for diagnostic imaging by administering ${ }^{18} \mathrm{~F}$-fluorothymidine and using PET to detect the accumulation of this tracer within tumor cells, as this analog of thymidine cannot incorporate into tumor cell DNA but remains trapped intracellularly following phosphorylation (200). Further development of these metabolomic imaging markers, alongside vascular-based approaches, continues to expand the range of diagnostic tools available for managing and treating RCC risk and progression.

\section{Conclusion}

The family of hereditary RCCs have contributed enormous insight into the mechanisms of angiogenesis and associated changes in metabolism that not only facilitate tumor growth, but 
act as drivers in the process of tumorigenesis. These core features of the RCC family of tumors have led to new insights in cancer biology and normal cellular physiology. Importantly, they also have satisfied the urgent need to create avenues for therapeutic intervention, and clinical tools such as imaging diagnostics, to enhance the care of patients with cancer. The future holds novel ways to integrate these tools into evolving treatment paradigms, such as immunotherapy, and to benefit the patients with familial syndromes themselves, through early detection, prevention, and therapeutic intervention.

\section{Acknowledgments}

This Review was funded by the NIH (R56HL133826 to JCC and R01CA198482 to WKR).

Address correspondence to: W. Kimryn Rathmell, Department of Medicine, Division of Hematology and Oncology, Vanderbilt-Ingram Cancer Center, Vanderbilt University, 2220 Pierce Avenue, Preston Research Building, Suite 777, Vanderbilt University Medical Center, Nashville, Tennessee 37232, USA. Phone: 615.875.9731; Email: kimryn.rathmell@vanderbilt.edu.
1. Schmidt LS, Linehan WM. Genetic predisposition to kidney cancer. Semin Oncol. 2016;43(5):566-574.

2. Richards FM, et al. Mapping the Von HippelLindau disease tumour suppressor gene: identification of germline deletions by pulsed field gel electrophoresis. Hum Mol Genet. 1993;2(7):879-882.

3. Lindau A. Zur frage der angiomatosis retinæ und ihrer hirnkomplikationen. Acta Ophthalmologica. 1926;4(1-2):193-226.

4. von Hippel E. Über eine sehr seltene Erkrankung der Netzhaut. Albrecht von Graefes Archiv für Ophthalmologie. 1904;59:83-106.

5. Maher ER, et al. Von Hippel-Lindau disease: a genetic study. J Med Genet.1991;28(7):443-447.

6. Lee CM, et al. VHL Type $2 \mathrm{~B}$ gene mutation moderates HIF dosage in vitro and in vivo. Oncogene. 2009;28(14):1694-1705.

7. Hoffman MA, Ohh M, Yang H, Klco JM, Ivan M, Kaelin WG. von Hippel-Lindau protein mutants linked to type $2 \mathrm{C}$ VHL disease preserve the ability to downregulate HIF. Hum Mol Genet. 2001;10(10):1019-1027.

8. Hickey MM, Lam JC, Bezman NA, Rathmell WK, Simon MC. von Hippel-Lindau mutation in mice recapitulates Chuvash polycythemia via hypoxiainducible factor-2 $\alpha$ signaling and splenic erythropoiesis. J Clin Invest. 2007;117(12):3879-3889.

9. Hickey MM, et al. The von Hippel-Lindau Chuvash mutation promotes pulmonary hypertension and fibrosis in mice. JClin Invest. 2010;120(3):827-839.

10. Ghosh MC, Zhang DL, Ollivierre H, Eckhaus MA, Rouault TA. Translational repression of HIF2 $\alpha$ expression in mice with Chuvash polycythemia reverses polycythemia. JClin Invest. 2018;128(4):1317-1325.

11. Rathmell WK, Hickey MM, Bezman NA, Chmielecki CA, Carraway NC, Simon MC. In vitro and in vivo models analyzing von HippelLindau disease-specific mutations. Cancer Res. 2004;64(23):8595-8603.

12. Toro JR, et al. Mutations in the fumarate hydratase gene cause hereditary leiomyomatosis and renal cell cancer in families in North America. Am J Hum Genet. 2003;73(1):95-106.

13. Yamasaki $\mathrm{T}$, et al. Exploring a glycolytic inhibitor for the treatment of an FH-deficient type-2 papillary RCC. Nat Rev Urol. 2011;8(3):165-171.

14. Ratcliffe PJ. Fumarate hydratase deficiency and cancer: activation of hypoxia signaling? Cancer Cell. 2007;11(4):303-305.

15. Pollard PJ, et al. Accumulation of Krebs cycle intermediates and over-expression of HIF1alpha in tumours which result from germline FH and SDH mutations. Hum Mol Genet. 2005;14(15):2231-2239.

16. Isaacs JS, et al. HIF overexpression correlates with biallelic loss of fumarate hydratase in renal cancer: novel role of fumarate in regulation of HIF stability. Cancer Cell. 2005;8(2):143-153.

17. Shuch B, et al. Defining early-onset kidney cancer: implications for germline and somatic mutation testing and clinical management. J Clin Oncol. 2014;32(5):431-437.

18. Maxwell PH, Pugh CW, Ratcliffe PJ. Inducible operation of the erythropoietin $3^{\prime}$ enhancer in multiple cell lines: evidence for a widespread oxygen-sensing mechanism. Proc Natl Acad Sci US A. 1993;90(6):2423-2427.

19. Manalo DJ, et al. Transcriptional regulation of vascular endothelial cell responses to hypoxia by HIF-1. Blood. 2005;105(2):659-669.

20. Mole DR, et al. Genome-wide association of hypoxia-inducible factor (HIF)- $1 \alpha$ and HIF- $2 \alpha$ DNA binding with expression profiling of hypoxia-inducible transcripts. J Biol Chem. 2009;284(25):16767-16775.

21. Xia X, et al. Integrative analysis of HIF binding and transactivation reveals its role in maintaining histone methylation homeostasis. Proc Natl Acad Sci U S A. 2009;106(11):4260-4265.

22. Semenza GL. Oxygen homeostasis. Wiley Interdiscip Rev Syst Biol Med. 2010;2(3):336-361.

23. Wang GL, Jiang BH, Rue EA, Semenza GL. Hypoxia-inducible factor 1 is a basic-helixloop-helix-PAS heterodimer regulated by cellular O2 tension. Proc Natl Acad Sci U S A. 1995;92(12):5510-5514.

24. Villar D, et al. Cooperativity of stress-responsive transcription factors in core hypoxiainducible factor binding regions. PLoS One. 2012;7(9):e45708.

25. Seagroves T, Johnson RS. Two HIFs may be better than one. Cancer Cell. 2002;1(3):211-213.

26. Wiesener MS, et al. Widespread hypoxiainducible expression of HIF-2alpha in distinct cell populations of different organs. FASEB J. 2003;17(2):271-273.

27. Semenza GL. Hypoxia-inducible factors in physiology and medicine. Cell. 2012;148(3):399-408.

28. Semenza GL. Defining the role of hypoxia-inducible factor 1 in cancer biology and therapeutics. Oncogene. 2010;29(5):625-634.

29. Schito L, Semenza GL. Hypoxia-inducible factors: master regulators of cancer progression. Trends Cancer. 2016;2(12):758-770.
30. Semenza GL. Hypoxia-inducible factors: mediators of cancer progression and targets for cancer therapy. Trends Pharmacol Sci. 2012;33(4):207-214.

31. Kaelin WG. The von Hippel-Lindau tumour suppressor protein: $\mathrm{O} 2$ sensing and cancer. Nat Rev Cancer. 2008;8(11):865-873.

32. Schönenberger $D$, et al. Formation of renal cysts and tumors in Vhl/Trp53-deficient mice requires HIF1 $\alpha$ and HIF $2 \alpha$. Cancer Res. 2016;76(7):2025-2036.

33. Harten SK, et al. Regulation of renal epithelial tight junctions by the von Hippel-Lindau tumor suppressor gene involves occludin and claudin 1 and is independent of E-cadherin. Mol Biol Cell. 2009;20(3):1089-1101.

34. Raval RR, et al. Contrasting properties of hypoxiainducible factor 1 (HIF-1) and HIF-2 in von HippelLindau-associated renal cell carcinoma. Mol Cell Biol. 2005;25(13):5675-5686.

35. Mandriota SJ, et al. HIF activation identifies early lesions in VHL kidneys: evidence for site-specific tumor suppressor function in the nephron. Cancer Cell. 2002;1(5):459-468.

36. Gordan JD, et al. HIF-alpha effects on c-Myc distinguish two subtypes of sporadic VHLdeficient clear cell renal carcinoma. Cancer Cell. 2008;14(6):435-446.

37. Kaku H, et al. Positive correlation between allelic loss at chromosome 14q24-31 and poor prognosis of patients with renal cell carcinoma. Urology. 2004;64(1):176-181.

38. Alimov A, Sundelin B, Wang N, Larsson C, Bergerheim U. Loss of 14q31-q32.2 in renal cell carcinoma is associated with high malignancy grade and poor survival. Int JOncol. 2004;25(1):179-185.

39. Shen C, et al. Genetic and functional studies implicate HIF $1 \alpha$ as a $14 q$ kidney cancer suppressor gene. Cancer Discov. 2011;1(3):222-235.

40. Kondo K, Klco J, Nakamura E, Lechpammer M, Kaelin WG. Inhibition of HIF is necessary for tumor suppression by the von Hippel-Lindau protein. Cancer Cell. 2002;1(3):237-246.

41. Chen W, et al. Targeting renal cell carcinoma with a HIF-2 antagonist. Nature. 2016;539(7627):112-117.

42. Cho H, et al. On-target efficacy of a HIF- $2 \alpha$ antagonist in preclinical kidney cancer models. Nature. 2016;539(7627):107-111.

43. Smith K, Gunaratnam L, Morley M, Franovic A, Mekhail K, Lee S. Silencing of epidermal growth factor receptor suppresses hypoxia-inducible factor-2-driven $\mathrm{VHL}^{-1}$ renal cancer. Cancer Res. 2005;65(12):5221-5230. 
44. Shinojima T, Oya M, Takayanagi A, Mizuno R, Shimizu N, Murai M. Renal cancer cells lacking hypoxia inducible factor (HIF)-1alpha expression maintain vascular endothelial growth factor expression through HIF-2 $\alpha$. Carcinogenesis. 2007;28(3):529-536.

45. Bertout JA, et al. HIF2 $\alpha$ inhibition promotes p53 pathway activity, tumor cell death, and radiation responses. Proc Natl Acad Sci U S A. 2009;106(34):14391-14396.

46. Kondo K, Kim WY, Lechpammer M, Kaelin WG. Inhibition of HIF2alpha is sufficient to suppress PVHL-defective tumor growth. PLoS Biol. 2003;1(3):E83.

47. Du W, et al. HIF drives lipid deposition and cancer in ccRCC via repression of fatty acid metabolism. Nat Commun. 2017;8(1):1769.

48. Qiu B, et al. HIF2 $\alpha$-dependent lipid storage promotes endoplasmic reticulum homeostasis in clear-cell renal cell carcinoma. Cancer Discov. 2015;5(6):652-667.

49. Rankin EB, et al. Direct regulation of GAS6/ AXL signaling by HIF promotes renal metastasis through SRC and MET. Proc Natl Acad Sci U S A. 2014;111(37):13373-13378.

50. Micucci C, Matacchione G, Valli D, Orciari S, Catalano A. HIF2 $\alpha$ is involved in the expansion of CXCR4-positive cancer stem-like cells in renal cell carcinoma. Br J Cancer. 2015;113(8):1178-1185.

51. Elorza A, et al. HIF2 $\alpha$ acts as an mTORC1 activator through the amino acid carrier SLC7A5. Mol Cell. 2012;48(5):681-691.

52. Zhang H, et al. HIF-1 inhibits mitochondrial biogenesis and cellular respiration in VHL-deficient renal cell carcinoma by repression of C-MYC activity. Cancer Cell. 2007;11(5):407-420.

53. Maranchie JK, Vasselli JR, Riss J, Bonifacino JS, Linehan WM, Klausner RD. The contribution of VHL substrate binding and HIF1-alpha to the phenotype of VHL loss in renal cell carcinoma. Cancer Cell. 2002;1(3):247-255.

54. Gordan JD, Simon MC. Hypoxia-inducible factors: central regulators of the tumor phenotype. Curr Opin Genet Dev. 2007;17(1):71-77.

55. Salama R, et al. Heterogeneous effects of direct hypoxia pathway activation in kidney cancer. PLoS One. 2015;10(8):e0134645.

56. Rankin EB, et al. Hypoxia-inducible factor- 2 regulates vascular tumorigenesis in mice. Oncogene. 2008;27(40):5354-5358.

57. Zimmer M, Doucette D, Siddiqui N, Iliopoulos O. Inhibition of hypoxia-inducible factor is sufficient for growth suppression of $\mathrm{VHL}^{-/-}$tumors. Mol Cancer Res. 2004;2(2):89-95.

58. Keith B, Johnson RS, Simon MC. HIF1 $\alpha$ and HIF $2 \alpha$ : sibling rivalry in hypoxic tumour growth and progression. Nat Rev Cancer. 2011;12(1):9-22.

59. Hanahan D, Weinberg RA. Hallmarks of cancer: the next generation. Cell. 2011;144(5):646-674.

60. Logsdon EA, Finley SD, Popel AS, Mac Gabhann F. A systems biology view of blood vessel growth and remodelling. J Cell Mol Med. 2014;18(8):1491-1508.

61. Rey S, Semenza GL. Hypoxia-inducible factor-1dependent mechanisms of vascularization and vascular remodelling. Cardiovasc Res. 2010;86(2):236-242.

62. Semenza GL. Regulation of vascularization by hypoxia-inducible factor 1. Ann N Y Acad Sci. 2009;1177:2-8.

63. Kaelin WG. The VHL tumor suppressor gene: insights into oxygen sensing and cancer. Trans Am Clin Climatol Assoc. 2017;128:298-307.

64. Kaelin WG. The von Hippel-Lindau tumor suppressor gene and kidney cancer. Clin Cancer Res. 2004;10(18 pt 2):6290S-6295S.

65. Iliopoulos O, Levy AP, Jiang C, Kaelin WG, Goldberg MA. Negative regulation of hypoxia-inducible genes by the von Hippel-Lindau protein. Proc Natl Acad Sci U S A .1996;93(20):10595-10599.

66. Chappell JC, et al. Flt-1 (VEGFR-1) coordinates discrete stages of blood vessel formation. Cardiovasc Res. 2016;111(1):84-93.

67. Peirce SM, Mac Gabhann F, Bautch VL. Integration of experimental and computational approaches to sprouting angiogenesis. Curr Opin Hematol. 2012;19(3):184-191.

68. Andrae J, Gallini R, Betsholtz C. Role of platelet-derived growth factors in physiology and medicine. Genes Dev. 2008;22(10):1276-1312.

69. Lindblom P, et al. Endothelial PDGF-B retention is required for proper investment of pericytes in the microvessel wall. Genes Dev. 2003;17(15):1835-1840.

70. Abramsson A, Lindblom P, Betsholtz C. Endothelial and nonendothelial sources of PDGF-B regulate pericyte recruitment and influence vascular pattern formation in tumors. JClin Invest. 2003;112(8):1142-1151.

71. Lindahl P, Johansson BR, Levéen P, Betsholtz C. Pericyte loss and microaneurysm formation in PDGF-B-deficient mice. Science. 1997;277(5323):242-245.

72. Hellström M, et al. Dll4 signalling through Notch1 regulates formation of tip cells during angiogenesis. Nature. 2007;445(7129):776-780.

73. Hosaka K, et al. Tumour PDGF-BB expression levels determine dual effects of anti-PDGF drugs on vascular remodelling and metastasis. Nat Commun. 2013;4:2129.

74. Hainsworth JD, et al. Treatment of advanced renal cell carcinoma with the combination bevacizumab/erlotinib/imatinib: a phase I/II trial. Clin Genitourin Cancer. 2007;5(7):427-432.

75. Xian X, et al. Pericytes limit tumor cell metastasis. J Clin Invest. 2006;116(3):642-651.

76. Erber R, et al. Combined inhibition of VEGF and PDGF signaling enforces tumor vessel regression by interfering with pericyte-mediated endothelial cell survival mechanisms. FASEB J. 2004;18(2):338-340.

77. Bergers G, Song S, Meyer-Morse N, Bergsland E, Hanahan D. Benefits of targeting both pericytes and endothelial cells in the tumor vasculature with kinase inhibitors. JClin Invest. 2003;111(9):1287-1295.

78. Pedrosa AR, et al. Endothelial Jagged1 promotes solid tumor growth through both pro-angiogenic and angiocrine functions. Oncotarget. 2015;6(27):24404-24423.

79. Kofler NM, Shawber CJ, Kangsamaksin T, Reed HO, Galatioto J, Kitajewski J. Notch signaling in developmental and tumor angiogenesis. Genes Cancer. 2011;2(12):1106-1116.

80. Li JL, et al. Delta-like 4 Notch ligand regulates tumor angiogenesis, improves tumor vascular function, and promotes tumor growth in vivo. Cancer Res. 2007;67(23):11244-11253.

81. Noguera-Troise I, et al. Blockade of Dll4 inhibits tumour growth by promoting non-productive angiogenesis. Nature. 2006;444(7122):1032-1037.

82. Ridgway J, et al. Inhibition of Dll4 signalling inhibits tumour growth by deregulating angiogenesis. Nature. 2006;444(7122):1083-1087.

83. Ubezio B, et al. Synchronization of endothelial Dll4-Notch dynamics switch blood vessels from branching to expansion. Elife. 2016;5:e12167.

84. Jakobsson L, et al. Endothelial cells dynamically compete for the tip cell position during angiogenic sprouting. Nat Cell Biol. 2010;12(10):943-953.

85. Siekmann AF, Lawson ND. Notch signalling limits angiogenic cell behaviour in developing zebrafish arteries. Nature. 2007;445(7129):781-784.

86. Krebs LT, Shutter JR, Tanigaki K, Honjo T, Stark KL, Gridley T. Haploinsufficient lethality and formation of arteriovenous malformations in Notch pathway mutants. Genes Dev. 2004;18(20):2469-2473.

87. Lawson ND, et al. Notch signaling is required for arterial-venous differentiation during embryonic vascular development. Development. 2001;128(19):3675-3683.

88. High FA, Lu MM, Pear WS, Loomes KM, Kaestner KH, Epstein JA. Endothelial expression of the Notch ligand Jagged 1 is required for vascular smooth muscle development. Proc Natl Acad Sci US A. 2008;105(6):1955-1959.

89. Volz KS, et al. Pericytes are progenitors for coronary artery smooth muscle. Elife. 2015;4:e10036.

90. Liu H, Kennard S, Lilly B. NOTCH3 expression is induced in mural cells through an autoregulatory loop that requires endothelial-expressed JAGGED1. Circ Res. 2009;104(4):466-475.

91. Wang $X$, et al. The role of angiopoietins as potential therapeutic targets in renal cell carcinoma. Transl Oncol. 2014;7(2):188-195.

92. Woolf AS, Gnudi L, Long DA. Roles of angiopoietins in kidney development and disease. J Am Soc Nephrol. 2009;20(2):239-244.

93. Tamaskar I, Dhillon J, Pili R. Resistance to angiogenesis inhibitors in renal cell carcinoma. Clin Adv Hematol Oncol. 2011;9(2):101-110.

94. Vortmeyer AO, Falke EA, Gläsker S, Li J, Oldfield EH. Nervous system involvement in von Hippel-Lindau disease: pathology and mechanisms. Acta Neuropathol. 2013;125(3):333-350.

95. Rosenblatt MI, Azar DT. Anti-angiogenic therapy: prospects for treatment of ocular tumors. Semin Ophthalmol. 2006;21(3):151-160.

96. Los M, et al. Elevated ocular levels of vascular endothelial growth factor in patients with von Hippel-Lindau disease. Ann Oncol. 1997;8(10):1015-1022.

97. Harris AL. von Hippel-Lindau syndrome: target for anti-vascular endothelial growth factor (VEGF) receptor therapy. Oncologist. 2000;5(suppl 1):32-36.

98. Arreola A, et al. Von Hippel-Lindau mutations disrupt vascular patterning and maturation via Notch. JCI Insight. 2018;3(4):92193.

99. Meng Q, et al. Hypoxia-inducible factor-dependent expression of angiopoietin-like 4 by conjunctival epithelial cells promotes the angiogenic phenotype of pterygia. Invest Ophthalmol Vis Sci. 2017;58(11):4514-4523. 
100.Hu K, et al. Hypoxia-inducible factor 1 upregulation of both VEGF and ANGPTL4 is required to promote the angiogenic phenotype in uveal melanoma. Oncotarget. 2016;7(7):7816-7828.

101.Jee K, et al. Expression of the angiogenic mediator, angiopoietin-like 4 , in the eyes of patients with proliferative sickle retinopathy. PLoS One. 2017;12(8):e0183320.

102. Rodrigues M, et al. Expression pattern of HIF-1 $\alpha$ and VEGF supports circumferential application of scatter laser for proliferative sickle retinopathy. Invest Ophthalmol Vis Sci. 2016;57(15):6739-6746.

103. Babapoor-Farrokhran S, et al. Angiopoietin-like 4 is a potent angiogenic factor and a novel therapeutic target for patients with proliferative diabetic retinopathy. Proc Natl Acad Sci U S A. 2015;112(23):E3030-E3039.

104. Wong WT, et al. Retinal vascular proliferation as an ocular manifestation of von Hippel-Lindau disease. Arch Ophthalmol. 2008;126(5):637-643.

105. Wong WT, Chew EY. Ocular von Hippel-Lindau disease: clinical update and emerging treatments. Curr Opin Ophthalmol. 2008;19(3):213-217.

106.Wong WT, et al. Clinical characterization of retinal capillary hemangioblastomas in a large population of patients with von Hippel-Lindau disease. Ophthalmology. 2008;115(1):181-188.

107. Haase VH, Glickman JN, Socolovsky M, Jaenisch $\mathrm{R}$. Vascular tumors in livers with targeted inactivation of the von Hippel-Lindau tumor suppressor. Proc Natl Acad Sci U S A. 2001;98(4):1583-1588.

108.van Rooijen E, et al. von Hippel-Lindau tumor suppressor mutants faithfully model pathological hypoxia-driven angiogenesis and vascular retinopathies in zebrafish. Dis Model Mech. 2010;3(5-6):343-353.

109. Okabe K, et al. Neurons limit angiogenesis by titrating VEGF in retina. Cell. 2014;159(3):584-596.

110. Hombrebueno JR, Ali IH, Xu H, Chen M. Sustained intraocular VEGF neutralization results in retinal neurodegeneration in the Ins2(Akita) diabetic mouse. Sci Rep. 2015;5:18316.

111. Hashimoto T, Zhang XM, Chen BY, Yang XJ. VEGF activates divergent intracellular signaling components to regulate retinal progenitor cell proliferation and neuronal differentiation. Development. 2006;133(11):2201-2210.

112. Chew EY. Ocular manifestations of von Hippel-Lindau disease: clinical and genetic investigations. Trans Am Ophthalmol Soc. 2005;103:495-511.

113. Vortmeyer AO, Alomari AK. Pathology of the nervous system in von Hippel-Lindau disease. J Kidney Cancer VHL. 2015;2(3):114-129.

114. Butman JA, Linehan WM, Lonser RR. Neurologic manifestations of von Hippel-Lindau disease. JAMA. 2008;300(11):1334-1342.

115. Gläsker S, Smith J, Raffeld M, Li J, Oldfield EH, Vortmeyer AO. VHL-deficient vasculogenesis in hemangioblastoma. Exp Mol Pathol. 2014;96(2):162-167.

116. Zhuang Z, et al. Tumor derived vasculogenesis in von Hippel-Lindau disease-associated tumors. Sci Rep. 2014;4:4102.

117. Kim BY, Jonasch E, McCutcheon IE. Pazopanib therapy for cerebellar hemangioblastomas in von Hippel-Lindau disease: case report. Target Oncol. 2012;7(2):145-149.
118. Wizigmann-Voos S, Breier G, Risau W, Plate KH. Up-regulation of vascular endothelial growth factor and its receptors in von Hippel-Lindau disease-associated and sporadic hemangioblastomas. Cancer Res. 1995;55(6):1358-1364.

119. Sanford M, Keating GM. Pazopanib: in advanced renal cell carcinoma. BioDrugs. 2010;24(5):279-286.

120. Gore ME, Larkin JM. Challenges and opportunities for converting renal cell carcinoma into a chronic disease with targeted therapies. $\mathrm{Br} J$ Cancer. 2011;104(3):399-406.

121. Kaelin WG. Treatment of kidney cancer: insights provided by the VHL tumor-suppressor protein. Cancer. 2009;115(10 suppl):2262-2272.

122. Lee CH, Motzer RJ. Kidney cancer in 2016: the evolution of anti-angiogenic therapy for kidney cancer. Nat Rev Nephrol. 2017;13(2):69-70.

123. Patel PH, Chadalavada RS, Chaganti RS, Motzer RJ. Targeting von Hippel-Lindau pathway in renal cell carcinoma. Clin Cancer Res. 2006;12(24):7215-7220.

124. Ma S, Pradeep S, Hu W, Zhang D, Coleman R, Sood A. The role of tumor microenvironment in resistance to anti-angiogenic therapy. F1000Res. 2018;7:326.

125. Haas NB, et al. Adjuvant sunitinib or sorafenib for high-risk, non-metastatic renal-cell carcinoma (ECOG-ACRIN E2805): a double-blind, placebo-controlled, randomised, phase 3 trial. Lancet. 2016;387(10032):2008-2016.

126. Karakiewicz PI, et al. Kidney Cancer Research Network of Canada consensus statement on the role of adjuvant therapy after nephrectomy for high-risk, non-metastatic renal cell carcinoma: a comprehensive analysis of the literature and meta-analysis of randomized controlled trials. Can Urol Assoc J. 2018;12(6):173-180.

127. Khan KA, Kerbel RS. Improving immunotherapy outcomes with anti-angiogenic treatments and vice versa. Nat Rev Clin Oncol. 2018;15(5):310-324.

128. Ramjiawan RR, Griffioen AW, Duda DG. Anti-angiogenesis for cancer revisited: is there a role for combinations with immunotherapy? Angiogenesis. 2017;20(2):185-204.

129. Lee K, Zhang H, Qian DZ, Rey S, Liu JO, Semenza GL. Acriflavine inhibits HIF-1 dimerization, tumor growth, and vascularization. Proc Natl Acad Sci U S A. 2009;106(42):17910-17915.

130. Harlander S, et al. Combined mutation in Vhl, Trp53 and Rb1 causes clear cell renal cell carcinoma in mice. Nat Med. 2017;23(7):869-877.

131. Yoon C, et al. Multimodal targeting of tumor vasculature and cancer stem-like cells in sarcomas with VEGF-A inhibition, HIF-1 $\alpha$ inhibition, and hypoxia-activated chemotherapy. Oncotarget. 2016;7(28):42844-42858

132. Ricketts CJ, Crooks DR, Linehan WM. Targeting HIF $2 \alpha$ in clear-cell renal cell carcinoma. Cancer Cell. 2016;30(4):515-517.

133. Kaelin WG. HIF2 inhibitor joins the kidney cancer armamentarium. J Clin Oncol. 2018;36(9):908-910.

134. Jilaveanu LB, et al. Tumor microvessel density as a prognostic marker in high-risk renal cell carcinoma patients treated on ECOG-ACRIN E2805. Clin Cancer Res. 2018;24(1):217-223.

135. Lunt SY, Vander Heiden MG. Aerobic glycolysis: meeting the metabolic requirements of cell proliferation. Annu Rev Cell Dev Biol. 2011;27:441-464.

136. Warburg O. On the origin of cancer cells. Science. 1956;123(3191):309-314.

137. Jiang BH, Agani F, Passaniti A, Semenza GL. V-SRC induces expression of hypoxia-inducible factor 1 (HIF-1) and transcription of genes encoding vascular endothelial growth factor and enolase 1: involvement of HIF-1 in tumor progression. Cancer Res. 1997;57(23):5328-5335.

138. Kim JW, Gao P, Liu YC, Semenza GL, Dang CV. Hypoxia-inducible factor 1 and dysregulated c-Myc cooperatively induce vascular endothelial growth factor and metabolic switches hexokinase 2 and pyruvate dehydrogenase kinase $1 . \mathrm{Mol}$ Cell Biol. 2007;27(21):7381-7393.

139. Semenza GL. Regulation of metabolism by hypoxia-inducible factor 1. Cold Spring Harb Symp Quant Biol. 2011;76:347-353.

140.Semenza GL, Wang GL. A nuclear factor induced by hypoxia via de novo protein synthesis binds to the human erythropoietin gene enhancer at a site required for transcriptional activation. Mol Cell Biol. 1992;12(12):5447-5454.

141. Ebert BL, Firth JD, Ratcliffe PJ. Hypoxia and mitochondrial inhibitors regulate expression of glucose transporter-1 via distinct Cis-acting sequences. J Biol Chem. 1995;270(49):29083-29089.

142.Iyer NV, et al. Cellular and developmental control of $\mathrm{O} 2$ homeostasis by hypoxia-inducible factor 1 alpha. Genes Dev. 1998;12(2):149-162.

143. Düvel K, et al. Activation of a metabolic gene regulatory network downstream of mTOR complex 1. Mol Cell. 2010;39(2):171-183.

144.Semenza GL, Roth PH, Fang HM, Wang GL. Transcriptional regulation of genes encoding glycolytic enzymes by hypoxia-inducible factor 1 . J Biol Chem. 1994;269(38):23757-23763.

145. Laughner E, Taghavi P, Chiles K, Mahon PC, Semenza GL. HER2 (neu) signaling increases the rate of hypoxia-inducible factor 1alpha (HIF1alpha) synthesis: novel mechanism for HIF-1mediated vascular endothelial growth factor expression. Mol Cell Biol. 2001;21(12):3995-4004.

146.Hudson CC, et al. Regulation of hypoxia-inducible factor 1alpha expression and function by the mammalian target of rapamycin. Mol Cell Biol. 2002;22(20):7004-7014.

147. Hu CJ, Wang LY, Chodosh LA, Keith B, Simon MC. Differential roles of hypoxia-inducible factor 1alpha (HIF-1 $\alpha)$ and HIF-2alpha in hypoxic gene regulation. Mol Cell Biol. 2003;23(24):9361-9374.

148. Brugarolas JB, Vazquez F, Reddy A, Sellers WR, Kaelin WG. TSC2 regulates VEGF through mTOR-dependent and -independent pathways. Cancer Cell. 2003;4(2):147-158.

149. Kim JW, Tchernyshyov I, Semenza GL, Dang CV. HIF-1-mediated expression of pyruvate dehydrogenase kinase: a metabolic switch required for cellular adaptation to hypoxia. Cell Metab. 2006;3(3):177-185.

150. Papandreou I, Cairns RA, Fontana L, Lim AL, Denko NC. HIF-1 mediates adaptation to hypoxia by actively downregulating mitochondrial oxygen consumption. Cell Metab. 2006;3(3):187-197.

151. Semenza GL, et al. Hypoxia response elements in the aldolase A, enolase 1, and lactate dehydrogenase A gene promoters contain essential binding 
sites for hypoxia-inducible factor 1.J Biol Chem. 1996;271(51):32529-32537.

152. Zhang H, et al. Mitochondrial autophagy is an HIF-1-dependent adaptive metabolic response to hypoxia. J Biol Chem. 2008;283(16):10892-10903.

153. Bellot G, et al. Hypoxia-induced autophagy is mediated through hypoxia-inducible factor induction of BNIP3 and BNIP3L via their BH3 domains. Mol Cell Biol. 2009;29(10):2570-2581.

154.Chan DA, Giaccia AJ. Hypoxia, gene expression, and metastasis. Cancer Metastasis Rev. 2007;26(2):333-339.

155. Chan SY, Zhang YY, Hemann C, Mahoney CE, Zweier JL, Loscalzo J. MicroRNA-210 controls mitochondrial metabolism during hypoxia by repressing the iron-sulfur cluster assembly proteins ISCU1/2. Cell Metab. 2009;10(4):273-284.

156. Favaro E, et al. MicroRNA-210 regulates mitochondrial free radical response to hypoxia and krebs cycle in cancer cells by targeting iron sulfur cluster protein ISCU. PLoS One. 2010;5(4):e10345.

157. Fukuda R, Zhang H, Kim JW, Shimoda L, Dang CV, Semenza GL. HIF-1 regulates cytochrome oxidase subunits to optimize efficiency of respiration in hypoxic cells. Cell. 2007;129(1):111-122.

158. Guzy RD, Schumacker PT. Oxygen sensing by mitochondria at complex III: the paradox of increased reactive oxygen species during hypoxia. Exp Physiol. 2006;91(5):807-819.

159. Noguchi T, Inoue H, Tanaka T. The M1- and M2-type isozymes of rat pyruvate kinase are produced from the same gene by alternative RNA splicing. J Biol Chem. 1986;261(29):13807-13812.

160.Luo W, et al. Pyruvate kinase M2 is a PHD3-stimulated coactivator for hypoxia-inducible factor 1 . Cell. 2011;145(5):732-744.

161. Filipp FV, Scott DA, Ronai ZA, Osterman AL, Smith JW. Reverse TCA cycle flux through isocitrate dehydrogenases 1 and 2 is required for lipogenesis in hypoxic melanoma cells. Pigment Cell Melanoma Res. 2012;25(3):375-383.

162.Gameiro PA, et al. In vivo HIF-mediated reductive carboxylation is regulated by citrate levels and sensitizes VHL-deficient cells to glutamine deprivation. Cell Metab. 2013;17(3):372-385.

163. Metallo CM, et al. Reductive glutamine metabolism by IDH1 mediates lipogenesis under hypoxia. Nature. 2011;481(7381):380-384.

164. Mullen AR, et al. Reductive carboxylation supports growth in tumour cells with defective mitochondria. Nature. 2011;481(7381):385-388.

165. Wise DR, et al. Hypoxia promotes isocitrate dehydrogenase-dependent carboxylation of $\alpha$-ketoglutarate to citrate to support cell growth and viability. Proc Natl Acad Sci U S A. 2011;108(49):19611-19616.

166. Kim W, Kaelin WG. The von Hippel-Lindau tumor suppressor protein: new insights into oxygen sensing and cancer. Curr Opin Genet Dev. 2003;13(1):55-60.

167. Hu H, Takano N, Xiang L, Gilkes DM, Luo W, Semenza GL. Hypoxia-inducible factors enhance glutamate signaling in cancer cells. Oncotarget. 2014;5(19):8853-8868.

168. Stepulak A, et al. Expression of glutamate receptor subunits in human cancers. Histochem Cell Biol. 2009;132(4):435-445.

169. Hart GW, Slawson C, Ramirez-Correa G, Lagerlof O. Cross talk between O-GlcNAcylation and phosphorylation: roles in signaling, transcription, and chronic disease. Annu Rev Biochem. 2011;80:825-858.

170.Lynch TP, Reginato MJ. O-GlcNAc transferase: a sweet new cancer target. Cell Cycle. 2011;10(11):1712-1713.

171. Ferrer CM, et al. O-GlcNAcylation regulates cancer metabolism and survival stress signaling via regulation of the HIF-1 pathway. Mol Cell. 2014;54(5):820-831.

172. Taylor CT, Colgan SP. Regulation of immunity and inflammation by hypoxia in immunological niches. Nat Rev Immunol. 2017;17(12):774-785.

173. Siska PJ, et al. Mitochondrial dysregulation and glycolytic insufficiency functionally impair CD8 $\mathrm{T}$ cells infiltrating human renal cell carcinoma. JCI Insight. 2017;2(12):93411.

174. Rosen MA, Schnall MD. Dynamic contrastenhanced magnetic resonance imaging for assessing tumor vascularity and vascular effects of targeted therapies in renal cell carcinoma. Clin Cancer Res. 2007;13(2 pt 2):770s-776s.

175. Barrett T, Brechbiel M, Bernardo M, Choyke PL. MRI of tumor angiogenesis. J Magn Reson Imaging. 2007;26(2):235-249.

176. Hillman GG, et al. Dynamic contrast-enhanced magnetic resonance imaging of vascular changes induced by sunitinib in papillary renal cell carcinoma xenograft tumors. Neoplasia. 2009;11(9):910-920.

177. Chen Y, Zhang J, Dai J, Feng X, Lu H, Zhou C. Angiogenesis of renal cell carcinoma: perfusion CT findings. Abdom Imaging. 2010;35(5):622-628.

178. Herts BR. Imaging for renal tumors. Curr Opin Urol. 2003;13(3):181-186.

179. Wang JH, et al. Dynamic CT evaluation of tumor vascularity in renal cell carcinoma. AJR Am J Roentgenol. 2006;186(5):1423-1430.

180. Rehman S, Jayson GC. Molecular imaging of antiangiogenic agents. Oncologist. 2005;10(2):92-103.

181. Sacco E, et al. Imaging of renal cell carcinoma: state of the art and recent advances. Urol Int . 2011;86(2):125-139.

182.Turkbey B, Kobayashi H, Ogawa M, Bernardo $\mathrm{M}$, Choyke PL. Imaging of tumor angiogenesis: functional or targeted? AJR Am J Roentgenol. 2009;193(2):304-313.

183. Cai W, Chen X. Multimodality imaging of vascular endothelial growth factor and vascular endothelial growth factor receptor expression. Front Biosci. 2007;12:4267-4279.

184. Niccoli Asabella A, Di Palo A, Altini C, Ferrari C, Rubini G. Multimodality imaging in tumor angiogenesis: present status and perspectives. Int J Mol
Sci. 2017;18(9):E1864.

185. Wang J, Qin B, Chen X, Wagner WR, Villanueva FS. Ultrasound molecular imaging of angiogenesis using vascular endothelial growth factor-conjugated microbubbles. Mol Pharm. 2017;14(3):781-790.

186. Rojas JD, et al. Ultrasound molecular imaging of VEGFR-2 in clear-cell renal cell carcinoma tracks disease response to antiangiogenic and notchinhibition therapy. Theranostics. 2018;8(1):141-155.

187. Ellegala DB, et al. Imaging tumor angiogenesis with contrast ultrasound and microbubbles targeted to alpha(v)beta3. Circulation. 2003;108(3):336-341.

188. Backer MV, et al. Molecular imaging of VEGF receptors in angiogenic vasculature with single-chain VEGF-based probes. Nat Med. 2007;13(4):504-509.

189. Kochhar R, Brown RK, Wong CO, Dunnick NR, Frey KA, Manoharan P. Role of FDG PET/CT in imaging of renal lesions. J Med Imaging Radiat Oncol. 2010;54(4):347-357.

190. Kayani I, et al. Sequential FDG-PET/CT as a biomarker of response to Sunitinib in metastatic clear cell renal cancer. Clin Cancer Res. 2011;17(18):6021-6028.

191. Harrison MR, George DJ. Better late than early: FDG-PET imaging in metastatic renal cell carcinoma. Clin Cancer Res. 2011;17(18):5841-5843.

192. Kang DE, White RL, Zuger JH, Sasser HC, Teigland CM. Clinical use of fluorodeoxyglucose $\mathrm{F} 18$ positron emission tomography for detection of renal cell carcinoma. JUrol. 2004;171(5):1806-1809.

193. Khandani AH, Rathmell WK. Positron emission tomography in renal cell carcinoma: an imaging biomarker in development. Semin Nucl Med. 2012;42(4):221-230.

194. Liu Y. The place of FDG PET/CT in renal cell carcinoma: value and limitations. Front Oncol. 2016;6:201.

195. Kurata T, Oguri T, Isobe T, Ishioka S, Yamakido M. Differential expression of facilitative glucose transporter (GLUT) genes in primary lung cancers and their liver metastases. Jpn J Cancer Res. 1999;90(11):1238-1243.

196. Grassi I, et al. The clinical use of PET with (11)C-acetate. Am J Nucl Med Mol Imaging. 2012;2(1):33-47.

197. Maleddu A, et al. 11C-acetate PET for early prediction of sunitinib response in metastatic renal cell carcinoma. Tumori. 2009;95(3):382-384.

198.Zhu A, Lee D, Shim H. Metabolic positron emission tomography imaging in cancer detection and therapy response. Semin Oncol. 2011;38(1):55-69.

199.Kitajima K, et al. 11C-Choline positive but 18F-FDG negative pancreatic metastasis from renal cell carcinoma on PET. Nagoya J Med Sci. 2017;79(2):273-277.

200.Horn KP, et al. FDG and FLT-PET for early measurement of response to $37.5 \mathrm{mg}$ daily sunitinib therapy in metastatic renal cell carcinoma. Cancer Imaging. 2015;15:15. 